\title{
Proposed reforms in medical education in India: Perspective of undergraduate students
}

\author{
Dhruv Kapoor, Kokil Tiwari, Arjumand Faruqi, Arpit Garg, Shashank Gupta, Shobhit Nain, \\ Shally Awasthi* \\ King George's Medical University, Uttar Pradesh, India
}

A R T I C L E IN F O

\section{Keywords:}

Medical education

India

Qualitative research

Curriculum

Innovation

\begin{abstract}
A B S T R A C T
Introduction: Indian medical schools contribute significantly to the global pool of doctors. To strengthen the medical education system further, this study was aimed at identifying existing lacunae and proposing solutions, from perspective of medical undergraduates.

Methodology: Medical undergraduates participated in group discussions under mentorship of an expert in medical education. Identification and prioritisation of problems was done based on demand and impact on medical education. After critically reviewing available literature, solutions were reached by consensus.

Results: Six interested students participated in discussions. Classification of identified problems was done into domains of knowledge, skill training, and research. Major problems in 'knowledge' were: inefficient utilisation of time of students and teachers, and unyielding assessments; in 'skill training': inadequate training in skills; and in 'research': insufficient awareness and interest in research among undergraduates. Some solutions suggested for respective domains were prioritisation of teaching and training of medical students, advocation of innovative methods of teaching and assessment like flipped classroom approach and clinical vignettes respectively; early initiation of undergraduate training in skill development following the principle of competency-based education; and sensitization of undergraduates towards research by introducing it as basic core and advanced elective subject, besides setting up research advisory cells and organising research conclaves.

Conclusion: Problems were classified into domains of knowledge, skill training, and research. Proposed solutions involve a radical alteration in perception of students and teachers in terms of teaching-learning principles. There is a need to highlight these points before policy makers and implementers for a more robust medical education system.
\end{abstract}

\section{Introduction}

The medical education (ME) is an ever-evolving field and has seen many advancements and revisions but seldom seen complete and proper implementation. Despite India producing some of the best healthcare professionals in the world, Indian medical education (IME) has yet to keep abreast of advancements in healthcare and technologies, and expanding societal demands from doctors. There is a need of a ME which is updated, more compatible with the prevalent systems of learning, teaching and assessing, and "wrings more value out of the unyielding asset of time". ${ }^{1}$ Addressal of this gap has received considerable attention by the faculty of medical institutes and the administration. To identify the existing lacunae in IME, and churn out solutions from the perspective of medical undergraduates, interested students indulged in a series of group discussions (GD) under the mentorship of a senior consultant well versed in ME.

\section{Methodology}

The study was conducted in September 2018 and October 2018 in King George's Medical University (KGMU), Uttar Pradesh, India. A group of students were assembled after ensuring at least one representative from each batch in medical school (except from the novice batch), of which the group leader (GL) was an MBBS Intern. The mentor was the Head of Department of Medical Education (DME), KGMU. Eight GDs were conducted, of which five were organised biweekly and moderated by the GL. All GDs were aimed at reaching a general consensus which was later on reviewed in the three, weekly discussions, moderated by the mentor.

The topics of the GDs were identification and prioritisation of

\footnotetext{
${ }^{*}$ Corresponding author.

E-mail address: shallyawasthi@kgmcindia.edu (S. Awasthi).
} 
Table 1

Lacunae identified in the domains of medical education and solutions proposed for them.

\begin{tabular}{|c|c|c|}
\hline Domain & Identified Lacuna(e) & Proposed Solution(s) \\
\hline \multirow[t]{7}{*}{ Knowledge } & $\begin{array}{l}1 \text { Consideration of training of students secondary to healthcare } \\
\text { service delivery }\end{array}$ & 1 Teaching and training of students to be given top priority. \\
\hline & 2 Use of less productive ways of teaching & 2a Optimization of student to teacher ratio \\
\hline & & $\begin{array}{l}\text { 2b Promotion of self-directed learning after basic training in subjects and addressal of queries by } \\
\text { experts }\end{array}$ \\
\hline & & $2 c$ Introduction of flipped classrooms and group discussions on cases \\
\hline & 3 Lack of practical relevance in teaching & 3 Competency-based education \\
\hline & 4 Inefficient internal assessment pattern. & 4 Frequent formative assessments with the use of clinical vignettes \\
\hline & $\begin{array}{l}5 \text { Improper utilisation of time of student and teacher due to } \\
\text { poor scheduling }\end{array}$ & 5 Improvement in scheduling and coordination in and between departments. \\
\hline \multirow[t]{3}{*}{ Skill } & 1 Inadequate training in clinical skills and ward procedures & $\begin{array}{l}1 \text { Involving undergraduates in bedside decision-making discussions and early initiation of } \\
\text { training in ward procedures. }\end{array}$ \\
\hline & 2 Lack of emergency training & 2 Compulsory emergency duties \\
\hline & 3 Deficient soft skill development & 3 Promotion of soft skills development \\
\hline
\end{tabular}

Research Lack of interest in research and its awareness among

Nurturing appropriate mindsets and sensitization of students to research. undergraduates

lacunae, brainstorming on solutions from review of literature to take leverage from experience of others, and critical appraisal of the identified lacunae and their solutions. The data was analysed using principles of statistics for qualitative data. The review of available literature in the past 15 years was done from PubMed and Google Scholar using the keywords: medical education, India, reforms, flipped classroom. However, a systematic review was not performed.

The conclusions of the study were finally presented in an open forum in the first Dr APJ Abdul Kalam Memorial Celebration, organised by DME, KGMU, on the theme of "Reforms in Medical Education" on October 15, 2018, in front of approximately 200 faculty members of KGMU, and heads of three universities.

\section{Results}

Six students participated of which two were females and four were males. The medical education was classified into the three major domains, knowledge, skill and research. In them, lacunae were identified and to them some solutions were also proposed, which are enlisted in Table 1.

Feedback was emphasized as an efficient tool for improvement.

\section{Discussion}

This study targets the foundation stone of an Indian medical practitioner, the IME, with the aim of finding lacunae and their appropriate solutions, by GDs among medical students. There have been studies which have explored medical education system of nations and universities. But there are only a few done on IME and that too by undergraduates.

This study found lacunae in undergraduate medical education in one university, and classified and detailed them in domains of knowledge, skill and research. Some solutions were also proposed. Qualitative methodology was adopted because it was a pilot study of very short duration. The results of this pilot were intended to inform university authorities on areas which could be strengthened.

To strengthen IME, there is a need of amending its three keystones: knowledge, skill training and research.

Most medical institutes in India aim at spoon-feeding students which ensures a stronghold on the existing knowledge of that subject but fails in inculcating the spirit of being a life-long self-inspired learner. ${ }^{2}$ Two methods of teaching were sought: GDs for better understanding in case presentations and flipped classrooms as an efficient replacement of didactic lectures. GDs would help inculcate the spirit and habit of peer review in addition to overcoming fear of public speaking and enforcing the fact that different sources provide different but valuable perspectives on the same case. It has been proven that the students perform significantly better when online learning was combined with face-to-face interactions as in flipped classrooms. ${ }^{3}$ The internal assessment can be strengthened by regular formative assessments using both multiple choice questions and subjective questions which would help in assessing students objectively and globally for all aspects of learning. Assessment of "higher order" skills of interpretation and problem-solving should be promoted with the use of clinical vignettes.

Skill training has a vital role in preparing students to become successful practitioners of clinical medicine. Competency-based education using principles of apprenticeship, should be used as an alternative to the currently used system so that the new doctor is capable of addressing the basic healthcare needs of the country. ${ }^{4,5}$ Early initiation of skill training both of ward procedures and soft skills, and early exposure to emergency settings should be done. Involving medical students in bedside decision-making discussions would instil a management-driven mindset and provide a platform to experience the metamorphosis of text into practice. The training of students must also include a compulsory training in principles of Basic Life Support, Advanced Trauma Life Support and Advanced Cardiac Life Support as medical emergency handling is a professional duty and societal expectation-cum-demand from a medical graduate.

The third domain of ME forms the cornerstone of development and progress. For research, the correct mindset is required and the best way is to nurture inquisitiveness from the beginning, which is the undergraduate level. Awareness and sensitization of students towards research and its potential was sought as the sole solution to this problem. A few ways to realize this solution are: including research as a subject. It could be divided into a core subject, which would be a must for the students, comprising of the basics of research methodology, basic tools of biostatistics and interpretation of research studies and papers; and an elective subject wherein the interested students would be introduced to further details and methods of research. Organization of research conclaves would also encourage an exchange of ideas and promote interdisciplinary interactions and exposure to other fields of science as well.

The study was based on recent first-hand experience of self-motivated students of all years of medical school. However, it suffered from limited participation and the views proposed could not be called representative. Also, it was not subjected to rigorous validation in and out of the system, as it was intended to be a student preliminary work. Findings of the study will be validated over a large group of students. These changes were thought of by the young minds and are subject to further improvement and debates.

IME has seen and is still in need of changes for a better structure. 
The proposed changes involve a radical alteration in the perception of students and teachers in terms of teaching-learning principles. Efficient ways of training and assessment must be employed focussing on competency-based education. Promoting awareness of research at a young age is the only way to nurture the correct mindsets. A strengthened feedback system can have a dramatic improvement in quality of ME. ${ }^{6}$ Keeping in view the need of changes, the Medical Council of India has taken a great step forward by revising the undergraduate medical education curriculum and its ways of teaching. It is hoped that the revised curriculum will be realized both in word and in spirit.

\section{Conflict of interest statement}

None stated.

\section{Acknowledgement}

A special thanks to administration of King George's Medical University, especially the Department of Medical Education, KGMU for their support and encouragement.

\section{Appendix A. Supplementary data}

Supplementary data to this article can be found online at https:// doi.org/10.1016/j.cegh.2019.03.012.

\section{References}

1. Prober CG, Heath C. Lecture halls without lectures-a proposal for medical education. N Engl J Med. 2012 May 3;366(18):1657-1659.

2. Cornwall M. Putting it into Practice: promoting independent learning in a traditional institution. In: Boud D, ed. Developing Student Autonomy in Learning. 1992; 1992:243-257 London, Kogan.

3. U.S. Department of Education. Office of Planning, Evaluation, and Policy Development. Evaluation of Evidence-Based Practices in Online Learning: A Meta-Analysis and Review of Online Learning Studies. Washington, D.C. 2010; 2010. [Last accessed on November 14, 2018]. Available from:. http://www2.ed.gov/rschstat/eval/tech/evidence-basedpractices/finalreport.pdf.

4. Medical Council of India. Vision 2015-National Meet on Implementation of Reforms in Undergraduate and Postgraduate Medical Education. New Delhi. 2011; 2011. [Last accessed on November 14, 2018]. Available from:. https://old.mciindia.org/tools/ announcement/MCI_booklet.pdf.

5. Majumder AA, D'Souza U, Rahman S. Trends in medical education: challenges and directions for need-based reforms of medical training in South-East Asia. Indian J Med Sci. 2004;58:369-380.

6. Lipnevich AA, Smith JK. Effects of differential feedback on students' examination performance. J Exp Psychol Appl. 2009 Dec;15(4):319. 